\title{
Review Article \\ The Influence of Arsenic, Lead, and Mercury on the Development of Cardiovascular Diseases
}

\author{
Peter Jennrich \\ Clinical Metal Toxicologist (IBCMT), Marienstraße 1, 97070 Wuerzburg, Germany \\ Correspondence should be addressed to Peter Jennrich; peter_jennrich@yahoo.de
}

Received 14 October 2012; Accepted 20 November 2012

Academic Editors: A. Pihlanto and H. Teragawa

Copyright (C) 2013 Peter Jennrich. This is an open access article distributed under the Creative Commons Attribution License, which permits unrestricted use, distribution, and reproduction in any medium, provided the original work is properly cited.

\begin{abstract}
As a group, cardiovascular disease (CVD) is the leading cause of death worldwide. It killed twice as many people as infectious and parasitic disease and three times as many people as all forms of cancer. There are other crucial risk factors next to the major risk factors identified by the Framingham Heart Study. In the last few years, detailed studies showed the correlation between environmental pollution and the development of CVD. The question, which environmental toxin is particularly harmful, is answered by CERCLA Priority List of Hazardous Substances with the following toxins: arsenic, lead, and mercury. The effect of these potential toxic metals on the development of cardiovascular diseases includes pathomechanisms as the accumulation of free radicals, damage of endothelial nitric oxide synthase, lipid peroxidation, and endocrine influences. This leads to the damage of vascular endothelium, atherosclerosis, high blood pressure, and an increased mortality from cardiovascular diseases. The cardiovascular effects of arsenic, lead, and mercury exposure and its impact on cardiovascular mortality need to be included in the diagnosis and the treatment of CVD.
\end{abstract}

\section{Introduction}

Cardiovascular disease is the genus for pathological change of heart, blood vessels, and blood flow. The fibrous change of arterial vascular walls is the mutual pathological correlate. Usually, it is caused by the damage of endothelium, which is the boundary layer between blood stream and vascular wall and has important functions in vasodilatation, modulation of inflammatory processes, and haemostasis. The interaction of nitric oxide (NO) via oxygen radicals, the reduction of nitric oxide synthase (NOS) cofactors as well as the inhibition of endothelial NOS itself through phosphorylation are regarded as central mechanisms of pathophysiology of endothelial dysfunction [1]. In the pathophysiology of atherosclerosis, the endothelial dysfunction fosters the adhesiveness of vascular wall for leukocytes, monocytes recruitment and transformation into foam cells, and finally the formation of vascular plaques. The endothelial dysfunction is considered as a great influence on the development of atherosclerosis and correlates with cardiovascular morbidity and mortality $[2,3]$.

In 2009 , barely $42 \%$ of all cases of death were caused by cardiovascular diseases. Those diseases particularly result in death among elderly people: most of the deceased people (91\%) were 65 years old and elder. All together, 150334 men and 206128 women died by the influence of vascular diseases. 60153 people died of a heart attack. Hence, in Germany, the disease of cardiovascular system is one of the most common causes of death as already in the preceding years [4]. Also in the USA, heart disease is the leading cause of death among men and women [5]. On the basis of 2005 mortality rate data, nearly 2400 Americans die of CVD each day-an average of 1 death every 37 seconds. About every 25 seconds, an American will have a coronary event, and about every minute someone will die from one [6]. In 2010, heart disease costs the United States nearly \$ 316.4 billion. This total includes the cost of health care services, medicates, and lost productivity [6]. As a group, CVD is the leading cause of death worldwide. According to the WHO in 2004, CVD accounted for nearly $30 \%$ of all deaths worldwide. It killed twice as many people as infectious and parasitic and 3 times as many people as all forms of cancer [7]. That clearly shows that the efforts of the national health care system in identifying the risk factors for cardiovascular diseases and the development of new strategies for prevention and treatment must be lit up. The 
major risk factors identified by the Framingham Heart Study are cigarette smoking, diabetes, hypertension, high serum cholesterol, and low HDL levels [8]. Numerous other secondary risk factors have also been associated with CVD risk. These include increased levels of triglycerides, C-reactive protein, lipoprotein (a), homocysteine, obesity, physical inactivity, small low-density lipoprotein particles, family history of premature CVD, and coagulation factor abnormalities. Beyond that, there are many studies which indicate a correlation between environmental pollution and the development of CVD $[9,10]$. The question, which environmental toxin is particularly harmful, is answered by CERCLA Priority List of Hazardous Substances. The Comprehensive Environment Response, Compensation, and Liability Act (CERCLA) has required the Agency for Toxic Substances and Disease Registry (ATSDR) and the United States Environmental Protection Agency (EPA) to prepare a list, in order of priority, of substances that are most commonly found at facilities on the National Priorities List (NPL) and which are determined to pose the most significant potential threat to human health due to their known or suspected toxicity and potential for human exposure at these NPL sites. It should be noted that this priority list is not a list of "most toxic" substances, but rather a prioritization of substances based on combination of their frequency, toxicity, and potential for human exposure [11]. Since 1997, there have been all together six updated versions of the Priority List of Hazardous Substances. The last version was presented in 2007. Frontrunner, in all six lists, remained unchanged arsenic (rank 1), lead (rank 2), and mercury (rank 3). Aim of this study is to point out which role these most hazardous substances play in the development of cardiovascular diseases.

\section{Methods}

To get an overview of the impact of arsenic, lead, and mercury for the development of cardiovascular diseases, the corresponding medical literature from 1960 to 2011 was collocated. Studies were identified from the medical database Medline (http://www.medline.de/k_finder.html) and PubMed (http://www.ncbi.nlm.nih.gov/pubmed/).

In addition, reference lists from relevant original research and review articles and documents were manually reviewed. In respective individual cases, the period of source search was additionally extended from 1898 to 1940 . Further, data from national and international institutions were also included for the search of the relevant literature. This includes: the World Health Organization (http://www.who.int/publications/en/), the American Agency for Toxic Substances and Disease Registry (http://www.atsdr.cdc.gov/), the American Food and Drug Administration (http://www.fda.gov/), the German Federal Statistical Office (http://www.destatis.de/), and the Swedish National Institute for Working Life (http://ebib.arbetslivsinstitutet.se) in cooperation with the United Nations Environment Programme (http://unep.org/). A selection has been made based on the variety of available information. For the information presented here, no claim for completeness can be raised. Thus, a qualitative review of the available evidence is presented.

\section{Results}

3.1. Arsenic. Arsenic is a naturally occurring element that is widely distributed in the Earth's crust. Arsenic is classified chemically as a metalloid, having both properties of a metal and a nonmetal. However, it is frequently referred to as a metal. Elemental arsenic is sometimes referred to as metallic arsenic. Arsenic is usually found in the environment combined with other elements such as oxygen, chlorine, and sulfur. Arsenic combined with these elements is called inorganic arsenic. Arsenic combined with carbon and hydrogen is referred to as organic arsenic [12]. Arsenic is the most hazardous substance because of its frequency, toxicity, and potential for human exposure [11]. This paper focuses on the cardiovascular effects of arsenic.

3.1.1. Cardiac Arrhythmias. In 1970, a case report of a patient with ventricular fibrillation associated with arsenic poisoning was published [13]. After the episode of ventricular fibrillation, the electrocardiogram showed nonspecific STsegment changes and prolongation of the Q-Tc interval. A case report of fatal cardiac arrhythmia in a patient with interstitial myocarditis related to chronic arsenic poisoning was published in 1989 [14]. Arsenic intoxication may be complicated by prolongation of the QT-U interval and torsade de pointes. T-U wave alternans occurs in the presence of a long QT-U interval and may be an electrocardiographic warning sign of torsade de pointes [15]. Prolongation of the QT interval and profound repolarization changes on electrocardiogram (ECG) have been reported in patients with acute promyelocytic leukemia (APL) treated with arsenic trioxide. This acquired form of long QT syndrome can result in life-threatening arrhythmias [16]. Unexplained early deaths observed in patients with APL treated with arsenic trioxide are potential due to arsenic-related cardiac toxicity and suggest that this agent, at the doses currently in use for the treatment of APL, may have more significant toxicity than previously recognized [17]. The association between chronic arsenic exposure and QT interval prolongation in a human population chronically exposed to arsenic via consumption of water from artesian wells was significant. QT interval may potentially be useful in the detection of early cardiac arsenic toxicity [16].

3.1.2. Peripheral Vascular Disease, Atherosclerosis, and Carotid Atherosclerosis. Next to proarrhythmic effects of arsenic trioxide and individual cases, which are indicative for the cardiac toxicity of arsenic compounds, epidemiological studies indicate an association between arsenic exposure and an increased incidence of vascular diseases, coronary heart disease, peripheral vascular disease, and strokes in particular [18]. Already at the end of the 19th century, it was reported about cases of preterm gangrene due to permanent consumption of arsenic water [19]. In the 1930s and 1940s, the correlation between chronic arsenic poisoning and peripheral circulation disturbance was ascertained, which was traced to the usage of pesticides containing arsenic often applied in viticulture [20]. 
The consumption of artesian well water with a high concentration of arsenic has been associated with the development of a unique peripheral vascular disease known as blackfoot disease (BFD), that was endemic in the Southwestern coastal area of Taiwan [21, 22]. In 2002, for the first time, the biological gradient between ingested arsenic by drinking water and carotid atherosclerosis before the development of clinical events such as acute myocardial infarction and stroke has been established. A dose-response relationship was observed between carotid atherosclerosis and serum level of total cholesterol, HDL cholesterol, LDL cholesterol, and triglycerides. All the biological gradients were statistically significant after adjustment age and sex (all probability values $<0.05)$. Subjects with the highest cumulative arsenic exposure $(\geq 20 \mathrm{mg} / \mathrm{L}$-years) had an increased risk of developing carotid atherosclerosis over those with the lowest arsenic exposure after adjustment for all other risk factors [23].

In Antofagasta, in the North of Chile, more than 250.000 people were subjected to drinking water with a concentration of arsenic with a content of $600 \mu \mathrm{g} / \mathrm{L}$ for over 39 years. Clinical studies on 180 exposed people associated increased incidence of abnormal cutaneous pigmentation, several circulatory disturbance (Raynaud's syndrome), or hyperkeratotic patches on palms and soles, particularly by children [24]. An autopsy finding on children in Antofagasta, Chile, with chronic arsenic intoxication had shown systemic arterial intimal thickening in small and medium-sized arteries involving the heart, gastrointestinal tract, liver, skin, and pancreas [25].These results indicate that accelerated arteriosclerosis can occur under chronic arsenic induction in the absence of traditional coronary risk factors [23].

One study showed the association between the longterm exposure to artesian well water and the change in microvascular circulation in the absence of peripheral arterial insufficiency [26].

3.1.3. Acute Myocardial Infarction. In Bangladesh, the groundwater contamination caused by inorganic arsenic is a massive public health hazard. It is estimated that 25 to 57 million people in Bangladesh have suffered from chronic exposure to arsenic over the last decades. The exposed population is at an elevated risk of arsenic-induced health problems. The principal cause of arsenic-induced mortality is cancer, particularly in bladder, lung, and liver. The overall mortality risk for the 3 cancers in combination was 103.5 per 100000 [27]. Next to the cancer risk, the analysis of a prospective cohort study in Bangladesh found a doseresponse relation between arsenic exposure and mortality from cardiovascular disease, especially heart disease, at a much lower level of arsenic exposure than previously reported [28]. Compared with lung and bladder cancer, acute myocardial infarction (AMI) mortality was the predominant cause of excess deaths during and immediately after a high arsenic-exposure period. Ten years after reduction of exposures, AMI mortality had decreased, and longer latency excess deaths from lung and bladder cancer predominated [29].

Residents in the arseniasis-endemic area in Taiwan had an increased risk of diabetes and its related vascular diseases compared with those in the nonendemic area. Therefore arsenic has been suggested to increase the risk of noninsulin-dependent diabetes mellitus and its related micro and macrovascular diseases [30]. The association between long-term exposure to arsenic and increased mortality from cardiovascular disease has also been reported among copper smelters in Sweden and the United States, among chimney sweeps in Sweden and Denmark, among glassblowers in Sweden, and among workers and neighbours of an arsenic refinery in Japan [31, 32].

3.1.4. Molecular Mechanisms of Cardiovascular Arsenic Toxicity. In addition to the epidemiologic findings, there are many data concerning the molecular changes of arsenic poisoning. These data explain the underlying mechanisms which are able to increase the cardiovascular risk after arsenic exposure.

(1) Arsenic Can Affect the Endothelial NO Synthase (eNOS). One of the proposed mechanisms for arsenic-induced vascular diseases is the disturbance of endothelial NO metabolism. Decreased serum concentrations of nitric oxide metabolites were found among Chinese in an endemic area of chronic arsenic poisoning in inner Mongolia. The mean blood concentration of total arsenic was six times higher in exposed subjects than in controls ( 42.1 versus $7.3 \mathrm{ng} / \mathrm{mL}$, $P<0.001)$. Mean serum concentration of nitrite/nitrate, stable metabolites of endogenous NO, was lower in arsenicexposed subjects than in controls (24.7 versus $51.6 \mathrm{microM}$, $P<0.001)$ [33]. Inhibition of the endothelial NO synthase (eNOS) leads to decreased availability of biologically active $\mathrm{NO}$ in the endothelium and is implicated in the pathophysiology of several vascular diseases [34].The decreased NO concentration leads to an arsenic-induced dysfunction in relaxation of blood vessels. This impairment of vasomotor tone due to arsenite exposure may be a contributing factor in the development of cardiovascular disease [35].

Furthermore the production of peroxynitrite, a strong oxidant formed from the coupling of nitric oxide and superoxide anion, was significantly increased in bovine aortic endothelial (BAE) cells exposed to sodium arsenite at concentrations as low as 0.5 microM [36]. Expression of the inflammatory mediator cyclooxygenase-2 (COX-2) was also upregulated in response to arsenite exposure as demonstrated by Western blot analysis. Nitration of COX-2 was detected in arsenic-treated cells, but not in untreated control cells. The findings suggest an increase in reactive species, notably peroxynitrite, in BAE cells exposed to arsenic. Moreover, the induction of important inflammatory mediators such as COX-2 may exacerbate the inflammatory state typical of atherosclerosis in response to arsenite exposure [36].

This stresses the correlation between inflammation and reactive oxygen species and NO. Inflammatory reactions induce the production of reactive oxygen species [37], and the disturbance of NO metabolism has been caused by ROS to a large extent [38].

(2) Arsenic Stimulates Reactive Oxygen Species and Has Inhibitory Effects on the Mitochondrial Respiratory Function. In addition to the inhibition of the eNOS, during exposure to arsenic, overproduction of reactive oxygen species can 
occur, resulting in oxidative stress, which is another major risk factor for vascular dysfunction [34]. Arsenic exposure in environmentally exposed children was positively associated with basal levels of NO- and $\mathrm{O} 2-$ in peripheral blood, mononuclear cells, and monocytes, pointing at As induced oxidative stress in circulating blood cells. Additionally, a positive association of $\mathrm{O} 2-$ production with inorganic As metabolites in stimulated monocytes was shown. It is suggested that these cells, and particularly the $\mathrm{O} 2-$ activation pathway, are relevant targets for As toxicity [39]. Arsenite also induces cell-apoptosis by the generation of hydrogen peroxide [40].

The relationship between the ingestion of arseniccontaminated well water and the level of reactive oxidants and antioxidant capacity in plasma was investigated in 2001. Sixty-four study subjects aged 42-75 were selected from the region of the Lanyang Basin on the Northeast coast of Taiwan, where arsenic content in well water varies from 0 to $\geq 3,000 \mu \mathrm{g} / \mathrm{L}$. The level of arsenic concentration in whole blood of study subjects showed a positive association with the level of reactive oxidants in plasma $(r=+0.41, P=$ $0.001)$ and an inverse relationship with the level of plasma antioxidant capacity $(r=-0.30, P=0.014)$. These results imply that persistent oxidative stress in peripheral blood may be a mechanism underlying the atherosclerosis induced by long-term arsenic exposure [41].

It is well known that reactive oxygen species (ROS) overproduction leads to mitochondrial dysfunction [42]. Arsenic has inhibitory effects on the mitochondrial respiratory function of the cell. Changes in mitochondrial protein synthesis and innermembrane structural integrity might also play an important role for arsenic toxicity [23]. Arsenate leads to swelling and shrinking of mitochondria [43], which is caused by disruption of oxidative phosphorylation and a decrease in cellular production of ATP leading to the formation of ROS and induction of stress proteins [23, 44, 45]. This is followed by alterations in the mitochondrial structure which might result in cellular injury, necrosis, and/or apoptosis of endothelial cells.

(3) Lipid Peroxidation Increases after Arsenic Exposure. Lipid peroxidation as an oxidative damage of lipids caused by ROS play an important role in the development of cardiovascular diseases. Chronic arsenic exposure is correlated with elevated levels of lipid peroxides (LPO). The mean serum level of LPO was significantly higher among a population exposed to high levels of arsenic compared with a low-exposed group in Wuyuan, Inner Mongolia, China [46]. Malondialdehyde (MDA) as an index of lipid peroxidation can be measured in the blood plasma. The mean plasma MDA level in 103 workers of an optoelectronic industry was significantly higher than that in 67 referents. The levels of MDA in the exposed workers were correlated significantly with the levels of urinary gallium and arsenic [47].

(4) Arsenic-Induced Endothelial Cell Proliferation and Apoptosis. Due to arsenic exposure, overproduction of ROS can induce cell proliferation [48]. The production of reactive oxygen species has been implicated as the initial step in arsenic-induced endothelial cell proliferation as a mechanism proposed for arsenic-related atherosclerosis as well as arsenic-induced apoptosis [18]. Arsenite is able to induce apoptosis in a concentration- and time-dependent manner. An increase of intracellular peroxide levels was accompanied with arsenite-induced apoptosis, indicating that hydrogen peroxide might play a role as a mediator to induce apoptosis [49].

(5) Immunological and Rheological Effects. Inflammation is an emerging risk factor for CVD. The inflammatory cytokine tumour necrosis factor-alpha induces signalling pathways which results in endothelial dysfunction [50]. Chronic exposure to arsenic upregulates the expression of tumor necrosis factor-alpha, interleukin-1, vascular cell adhesion molecule, and vascular endothelial growth factor leading to various cardiovascular disorders [51]. Furthermore, the arsenic exposure has been noted to induce atherosclerosis by increasing the platelet aggregation and reducing fibrinolysis [51, 52].

(6) Genetic Factor. Genetic polymorphisms in glutathione S-transferase (GST) genes have influence on the glutathione concentration, which is a necessary enzyme in As metabolism. A longitudinal study in an As-endemic region in Bangladesh was conducted to examine the association between As-contaminated drinking water and toenail As content. Individuals possessing GSTT1-null genotypes had significantly more As in their toenails in contrast to GSTT1 wild-type individuals $(b=0.11 ; 95 \% \mathrm{CI}, 0.06-0.2)$. Therefore, it seems that GSTT1 modifies the relationship between inorganic As exposure and toenail inorganic As content [53]. New research results point out that arsenic precipitates and impairs arteriosclerosis in case of arising apolipoprotein $\mathrm{E}$ defect [54].

A significantly age- and gender-adjusted odds ratio of 2.0 for the development of carotid atherosclerosis was observed in study subjects with epsilon4 allele of APOE than those without epsilon4 allele [55]. These genetic findings point to different individual tolerance against arsenic.

It clarifies the phenomenon that some people who are exposed to arsenic become ill, while others who are living under the same environmental conditions stay well.

3.2. Lead. Lead is a naturally occurring metal found in small amounts in the earth's crust. Lead can be found in all parts of our environment. Much of it comes from human activities including burning fossil fuels, mining, and manufacturing.

Lead cannot be degraded from humans and animals. The human body cannot use lead but will absorb and store it, as if it was calcium or phosphorus. Under continuous exposure, lead is stored in various organs and tissues, especially the bones and teeth. The amount of lead stored in a person's body is called their "body burden" [56]. The lead body burden is caused by occupational or environmental exposure to lead.

More than 100 years ago, the first reports suggested a link between lead exposure and cardiovascular outcomes. Decades of research later in December 2006 a systematic review concerning lead exposure and cardiovascular disease was published in the peer-reviewed monthly journal of 
the U.S. National Institute of Environmental Health Sciences, National Institutes of Health, Department of Health and Human Services [57]. The authors concluded that the evidence was sufficient to infer a causal relationship of lead exposure with hypertension. They required that these findings should have immediate public health implications such as the current occupational safety standards for blood lead must be lowered as a criterion for screening elevated lead exposure the needs to be established by adults.

3.2.1. Lead and Hypertension. Results from a cross-sectional sample of 2165 women aged 40 to 59 years, who participated in a household interview and physical examination, from the Third National Health and Nutrition Examination Survey conducted from 1988 to 1994 showed a positive correlation between blood lead levels and high blood pressure. At levels well below the US occupational exposure limit guidelines $(40 \mu \mathrm{g} / \mathrm{dL})$ at that time, blood lead level is positively associated with both systolic and diastolic blood pressure and risks of both systolic and diastolic hypertension among women aged from 40 to 59 years. The relationship between blood lead level and systolic and diastolic hypertension is most pronounced in postmenopausal women [58]. There is a relation between the bone turnover, the elevated blood lead level, and the high blood pressure in postmenopausal women. The skeleton is the major endogenous source of lead in circulating blood, particularly under conditions of accelerated bone turnover and mineral loss, such as during pregnancy and in postmenopausal osteoporosis. Findings of the Normative Aging Study provide evidence that bone resorption influences the release of bone lead stores into the circulation [59]. Important is that relatively low levels of lead in the blood are associated with cardiovascular outcomes [57]. So, it is possible that even small amounts of lead from occupational or environmental exposure, which are stored in bones, result in high blood pressure.

A high bone turnover occurs also in the course of pregnancy. The examination of 1017 pregnant women between 2003 and 2005 for the EDEN (Etude des Determinants pre et post natals du developpement et de la sante de l' Enfant) cohort study demonstrated the effect of blood lead levels on blood pressure and the incidence of pregnancy-induced hypertension (PIH) in the second and third trimesters of pregnancy. Lead levels were significantly higher in PIH cases (mean $\pm \mathrm{SD}, 2.2 \pm 1.4 \mu \mathrm{g} / \mathrm{dL}$ ) than in normotensive patients $(1.9 \pm 1.2 \mu \mathrm{g} / \mathrm{dL} ; P=0.02)[60]$.

For many years, the relationship of lead exposure and high blood pressure was studied in battery, ceramic, pigment, refinery, and smelter industries [57].

Furthermore, it was concluded, that in general populations, with mean blood lead levels of $0,4 \mathrm{umol} / \mathrm{l}$ or higher, there is an increase of systolic and/or diastolic blood pressure by approximately $1 \mathrm{mmHg}$ for each doubling of blood lead in the low range [61].

Until 2007, data from more than 30 original studies and around 60,000 participants have been summarized in divers reviews and meta-analyses. They have examined the evidence relating blood lead to blood pressure or hypertension. All these reviews concluded that there was a positive association between blood lead levels and blood pressure [57].

These associations have been observed at blood lead levels well below $5 \mu \mathrm{g} / \mathrm{dL}$ indicating that the U.S. Centers for Disease Control and Prevention criterion for elevated blood levels in children $(10 \mu \mathrm{g} / \mathrm{dL})$ is too high for adults [57].

\subsubsection{Coronary Heart Disease, Stroke, and Peripheral Arterial} Disease. The association of lead exposure and cardiovascular mortality in the USA was evaluated by using mortality followup data for participants of the Second National Health and Nutrition Examination Survey, a national cross-sectional survey of the general population conducted from 1976 to 1980. Survey participants aged from 30 to 74 years with blood lead measurements were followed up through December 31, $1992(n=4292)$. The evaluation showed that individuals with blood lead levels of 20 to $29 \mathrm{micro}$ g/dL in 1976 to 1980 (15\% of the US population at that time) experienced significantly increased circulatory and cardiovascular mortality from 1976 to 1992 [62].

The Third National Health and Nutrition Examination Survey confirmed and updated these findings. Blood lead levels were measured in a nationally representative sample of 13946 adults recruited from 1988 to 1994 and followedup for up to 12 years for all-cause and cause-specific mortality.

In this large population-based prospective study, a direct association between higher blood lead and increased mortality was identified at substantially lower blood lead levels than reported previously. An increased risk of cardiovascular, myocardial infarction and stroke mortality was evident at blood lead levels $>0.10 \mu \mathrm{mol} / \mathrm{L}(2.0 \mu \mathrm{g} / \mathrm{dL})$ [63].

A study from Denmark includes 1,052 men and women from Copenhagen County, who were examined in 1976 and 1981. In 1987, only the men were examined. This study showed a significant univariate association with total mortality, coronary heart disease, and cardiovascular disease, supporting the hypothesis of a causal association between blood lead and blood pressure, total mortality, coronary heart disease, and cardiovascular disease. The importance of this association was very modest for the individual, but the authors reasoned that the population's attributable risk might be considerable [64].

3.2.3. Molecular Mechanisms of Cardiovascular Lead Toxicity. The molecular mechanisms of lead toxicity, which results in poor cardiovascular outcome of lead exposed people, include lead induced oxidative stress, inactivation of nitric oxide, changes in beta-receptor density, endocrine effects, renalimpairment, and lipid peroxidation.

(1) Renal Impairment. The potential renal effects of lead extend from reversible proximal tubular dysfunction and ultrastructural changes to a chronic nephropathy and renal failure [65]. Renal tubular dysfunction is often present in children with acute lead intoxication and is shown by excessive aminoaciduria, glucosuria, and hyperphosphaturia [66]. The pathogenesis of chronic lead nephropathy is a continuum of morphological and functional change that can be divided into at least two stages. In an early phase, lasting less than 
one year, the proximal renal tubular cells form nuclear inclusion bodies. During this phase, there is also a relatively high urinary output of lead but no impairment of renal function. The ultrastructural changes are probably reversible. In a second phase, after four or more years of exposure, the proximal tubular cells apparently have decreased their ability to form nuclear inclusions, and the kidneys excrete less lead and morphologically have a moderate degree of interstitial fibrosis. This phase is not characterized by any gross impairment of renal function, but it is doubtful whether the morphological changes are completely reversible [67].

In 1992, it was shown that lead exposure is associated with a decrease in creatinine clearance in the general population [68]. The cumulative past lead absorption in 48 men diagnosed as having essential hypertension was measured via the EDTA lead-mobilization test. Patients who had hypertension with reduced renal function (i.e., serum creatinine level > $1.5 \mathrm{mg}$ per deciliter $(133 \mu \mathrm{mol}$ per liter $))$ had significantly larger amounts of mobilizable lead than did patients who had hypertension without renal impairment. Thus, lead may have an etiologic role in the renal disease of some patients usually designated as having "essential" hypertension [69].

(2) Free Radicals. Lead-induced oxidative stress has been identified as the primary contributory agent in the pathogenesis of lead poisoning. ROS generated as a result of lead exposure have been identified in endothelial tissue [70].

Lead toxicity leads to free radical damage via two separate, although related, pathways. One is the generation of reactive oxygen species, including hydroperoxides, singlet oxygen, and hydrogen peroxide; the other is the direct depletion of antioxidant reserves [71]. Lead effectively inactivate the glutathione molecule, so it is unavailable as an antioxidant [72]. Therefore, concentrations of glutathione in the blood of lead-exposed children, and adults have been shown to be significantly lower than control levels [73-75].

The enzyme glutathione reductase, which is responsible for recycling of glutathione from the oxidized form (glutathione disulfide) to the reduced form (reduced glutathione), is also deactivated by lead [76]. Depletion of intracellular glutathione is related with the mechanism of oxidized low density lipoproteins, which is a risk factor for atherosclerosis and CVD [77].

(3) Lipid Peroxidation. Furthermore lead-induced production of ROS results in lipid peroxidation and DNA damage [78]. Lipid peroxidation of cellular membranes has been identified as a result of lead exposure [79]. This is important for endothelial cells and for erythrocytes. Erythrocytes have a high affinity for lead, binding 99 percent of the lead in the bloodstream [71].

Lead is considered, along with silver, mercury, and copper, to be a strong hemolytic agent, able to cause erythrocyte destruction through the formation of lipid peroxides in cell membranes $[71,80]$.

(4) NO Deficiency. Nitric oxide, also known as "endotheliarelaxing factor," is effectively inactivated by ROS [71, 81]. ROS have been shown to oxidize NO in vascular endothelial cells, creating a NO deficiency and generating peroxynitrite, a highly active ROS that can damage lipids and DNA [71, 82]. Lead exposure has been shown to depress nitric oxide and cause hypertension $[71,83]$.

(5) Changes in Beta-Receptor Density and Endocrine Effects. Besides oxidative stress associated with functional NO deficiency, chronic lead exposure causes elevation of sympathetic activity with increased plasma norepinephrine level. This is coupled with depressed vascular and increased renal betareceptor densities and an activation of the renin-angiotensinaldosterone system. Furthermore, rise in endothelin production, reduction in vasodilatatory prostaglandins and elevation of vasoconstrictive prostaglandins were observed [84, 85]. These lead-induced molecular changes contribute to the elevation of blood pressure and lead-induced hypertension. The decrement of beta-adrenoceptor and cAMP in heart resulted in decreased contractility in heart [85].

3.3. Mercury. There are three categories of mercury compounds: organic, inorganic, and elemental. These forms are interconvertible, and all can produce systemic toxicity. At present, humans are exposed to mercury mostly through consumption of organic mercury-contaminated fish; the administration of thimerosal in vaccines and mercury from dental amalgams [86].

3.3.1. Mortality from Cardiovascular Diseases. An international mulitcenter research group studied the mortality caused by cardiovascular diseases after long-term exposure to inorganic mercury. Data from 6784 male and 265 female workers from four mercury mines and mills in Spain, Slovenia, Italy, and the Ukraine were examined. The workers were employed between 1900 and 1990. The follow-up period lasted from the 1950s to the 1990s. The mortality rate of the workers was compared with national reference rates. In all countries, an increased mortality from hypertension and from heart diseases other than ischaemic heart disease was found. The main causes of death in the category "heart diseases other than ischaemic" were chronic pulmonary heart disease in Slovenia (24/44 deaths), unspecified myocarditis in Italy (41/58 deaths), and cardiac arrest and unspecified heart disease in Spain (40/169 deaths each). The increase in death from hypertension was present only in Spain, and in Ukraine, whereas a decrease in the risk of this disease was found in the other countries. An increased mortality from cardiovascular diseases was apparent according to time since first exposure [87].

To investigate the relationship between mercury and cholesterol level in children, 274 children from three primary schools in South Korea were put under observation. The urine mercury were analysed by performing atomic absorption spectroscopy. The urine mercury concentrations were below the suggested level of concern according to the criteria of the Centers for Disease Control (CDC) and ATSDR. However, the urine mercury levels were associated with the serum cholesterol. So, the study suggests that mercury can induce an increase of cholesterol as a risk factor of myocardial infarction and coronary/cardiovascular disease even in very low concentrations [88]. 
In fish, mercury is in organic form, mainly as methylmercury, which is well absorbed in the gut and is accumulated in epithelial tissues including hair. The mercury content of hair is an indicator of mercury intake over several months [89].

3.3.2. Tachycardia. A 1999 case study presented an 11-yearold girl with hypertension and tachycardia. Excess urinary catecholamine excretion suggested pheochromocytoma, but imaging studies failed to demonstrate a tumour. Other symptoms included insomnia and weight loss. It was found that she had a raised concentration of mercury in blood and urine. It was said that mercury intoxication should be considered in the differential diagnosis of hypertension with tachycardia even in patients presenting without the skin lesions typical of mercury intoxication and without a history of exposure [90].

In 2007, a similar case was reported from China. A 10,5-year-old girl was found to have red painful hands, a blood pressure $170 / 120 \mathrm{~mm} \mathrm{Hg}(1 \mathrm{~mm} \mathrm{Hg}=0.133 \mathrm{kPa})$, tachycardia, and hypokalemia $(2.83-3.25 \mathrm{mmol} / \mathrm{L}$, reference value $3.5-5.5 \mathrm{mmol} / \mathrm{L}$ ). A raised concentration of mercury in urine $(0.171 \mathrm{mg} / \mathrm{L}$, reference value $<0.01 \mathrm{mg} / \mathrm{L})$ was found. The girl had been exposed to elemental mercury for several days. After chelating therapy, the girl's blood pressure and the tachycardia returned to normal; the erythromelalgia ameliorated and all other symptoms disappeared [91].

Two more cases of acute mercury poisoning by children occurred in the US state Michigan. A 4-year-old boy was seen at the emergency department because of new-onset seizures. He was found to have a blood pressure of $171 / 123 \mathrm{~mm}$ $\mathrm{Hg}$ land, heart rate of $164 /$ minute. During the following intensive medical examination, high catecholamine levels were found. Urinary norepinephrine was $72.1 \mu \mathrm{g} / 24$ hours $(n$ : $8-45)$. and vanillylmandelic acid was $13.6 \mathrm{mg} / \mathrm{g}$ of creatinine ( $n$ : $0-8.3$ ). The blood lead level was $<5 \mu \mathrm{g} / \mathrm{dL}$ (class I). The blood mercury level was $24 \mathrm{ng} / \mathrm{mL}(n:<9.9)$, and urinary mercury excretion was $324 \mu \mathrm{g} / 24$ hours $(n:<10)$. Chelation was initiated with British antilewisite (BAL) and changed to dimercaptosuccinic acid (DMSA) after consultation with a toxicologist. In 3 weeks, his symptoms improved via chelation and control of his hypertension. These findings were followed by an evaluation of the family. A foster sister had similar findings of rash and hypertension. Both had been exposed to elemental mercury in the home. The family was temporarily relocated, and chelation therapy was started. After 3 months of therapy, her blood pressure normalized, her urinary mercury excretion decreased, and she clinically recovered [92].

It can be difficult to differentiate mercury intoxication from pheochromocytoma and Kawasaki's disease, but mercury intoxication should be considered in a child with unexplained tachycardia, hypertension, mood changes, weight loss, and acrodynia. This is important because urinary mercury levels do not necessarily correlate with the severity of clinical signs and symptoms of mercury intoxication $[93,94]$.

Another case report was concerned with a 40 -year-old male with an acute mercury intoxication who showed also tachycardia as a main symptom [95].
3.3.3. Hypertension. The risk of hypertension increases with high hair and blood mercury levels [96-99]. Among Nunavik Inuit adults, mercury is associated with increasing blood pressure and pulse pressure. Pulse pressure is the difference between systolic and diastolic blood pressure. Mercury was positively correlated with systolic blood pressure $(r=0.25$; $P<0.0001)$ and pulse pressure $(r=0.33 ; P<0.0001)$. Mercury was negatively correlated with low frequency $(r=$ $-0.18 ; P=0.02)[96,97]$. According to the findings among Inuits, blood pressure was significantly associated with hair total $\mathrm{Hg}$ among a nonindigenous fish-eating population in the Brazilian Amazon [98].

In 2005, the relationship between mercury in blood and 24-h ambulatory blood pressure has been studied in four groups of healthy subjects: group 1, Danes living in Denmark consuming European food; group 2, Greenlanders living in Denmark consuming European food; group 3, Greenlanders living in Greenland consuming European food; and group 4, Greenlanders living in Greenland consuming mainly traditional Greenlandic food. Mercury in blood was highest in Greenlanders and increased when they lived in Greenland and consumed traditional Greenlandic food like sea mammals and fish. Mercury in blood was significantly and positively correlated to pulse pressure (rho $=0.272, P<$ $0.01)$ [100].

Comparisons between subjects with and without amalgam showed that amalgam-bearing subjects had significantly higher blood pressure, lower heart rate, lower hemoglobin, and lower hematocrit [101].

In a case study of an 17-year-old boy who was admitted to the hospital because of severe hypertension $(200 / 130 \mathrm{mmHg})$, headache, irritability, and sweating, initial biochemical tests suggested pheochromocytoma. The report of exposure to mercury vapor, $24 \mathrm{~h}$ urine screening, and measurement of blood mercury yet confirmed mercury intoxication. Remission of symptoms and normalization of blood pressure were achieved after 2 months by several courses of chelation therapy with dimercaprol (BAL) and penicillamine [102].

From 1986 to 1994, a unique population in the Faroe Islands was studied to examine prenatal methylmercury exposure as a cardiovascular risk factor. The mercury concentrations in cord blood and in maternal hair collected at parturition was analysed to assess prenatal exposure to methylmercury in a cohort of 1022 births during a 21-month period of 1986-1987. At the age 7 years, blood pressure, heart rate, and heart rate variability were determined. A total of 917 children (90,3\%) completed the examinations in 1993 and 1994.

After adjustment for body weight, diastolic, and systolic blood pressure increased by $13.9 \mathrm{mmHg}$ ( $95 \%$ confidence limits $(\mathrm{CL})=7.4,20.4)$ and $14.6 \mathrm{mmHg}(95 \% \mathrm{CL}=8.3$, 20.8), respectively, when cord blood mercury concentrations increased from 1 to $10 \mathrm{microg} / \mathrm{liter}$ cord blood. Above this level, which corresponds to a current exposure limit, no further increase was seen. Birth weight acted as a modifier, with the mercury effect being stronger in children with lower birth weights. In boys, heart rate variability decreased with increasing mercury exposures, particularly from 1 to 
$10 \mathrm{microg} / \mathrm{liter}$ cord blood, at which the variability was reduced by $47 \%$ (95\% CL $=14 \%, 68 \%)$. These findings from the Faroe Islands suggest that prenatal exposure to methylmercury may affect the development of cardiovascular homeostasis [103].

3.3.4. Carotid Atherosclerosis. In an epidemiologic cohort study, over 2-fold risk of acute myocardial infarction and mortality from coronary heart disease and cardiovascular disease in men in Eastern Finland with an elevated hair content of mercury was observed [104]. Also from Finland is the first documentation of the association between the accumulation of mercury in the human body and progressive course of atherosclerosis determined by ultrasonographic assessment of common carotid intima-media thickness (IMT), in a prospective study among 1014 men aged $42-60$ years. In a linear regression model adjusting for other atherosclerotic risk factors, high hair mercury content was one of the strongest predictors of the 4-year increase in the mean IMT $(P=0.0007)$. On the average, for each $\mathrm{mg} / \mathrm{g}$ increase in hair mercury content, there was an increment of $8 \mathrm{~mm}$ in the 4 year IMT increase. The findings suggest that mercury accumulation in the human body is associated with accelerated progression of carotid atherosclerosis [105]. The dependence between urinary mercury elimination and carotid intimamedia thickness is evidenced in nonsmoking workers. The occupational exposure to mercury vapour is related with early, asymptomatic carotid atherosclerosis [106].

\subsubsection{Myocardial Infarction and Cardiovascular Risk.} Because fish intake is a major source of exposure to mercury, the mercury content of fish may counteract the beneficial effects of its $n-3$ fatty acids. This is the result of an international case-control study. The study was conducted in eight European countries and Israel. The patients were 684 men with a first diagnosis of myocardial infarction. The controls were 724 men selected to be representative of the same populations. The joint association of mercury levels in toenail clippings and docosahexaenoic acid (DHA) levels in adipose tissue was evaluated with the risk of a first myocardial infarction among men. As a result, an independent and graded association between toenail mercury levels and the risk of myocardial infarction was found [107].

Similar results come from Finland. From the populationbased prospective Kuopio Ischaemic Heart Disease Risk Factor Study (KIHD), a cohort of 1871 Finnish men aged from 42 to 60 years, free of previous coronary heart disease (CHD) or stroke at baseline, was examined. Results indicated that high content of mercury in hair may be a risk factor for acute coronary events and CVD, CHD, and all-cause mortality in middle-aged eastern Finnish men. Mercury may also attenuate the protective effects of fish on cardiovascular health [108].

The mean urine concentration of mercury in 154 Polish chemical factory workers who used mercury in the chlorine production was $4.9 \pm 11.2 \mathrm{microg} / \mathrm{g}$ creatinine. The cardiovascular risk was higher in workers exposed to small or moderate mercury levels than in workers exposed to mercury vapor in high concentrations [109].

3.3.6. Thrombosis. Methylmercury induce platelet shape change and platelet aggregation [110]. Prolonged exposure to low-dose mercuric ion $\left(\mathrm{Hg}^{2+} ; 0.25-5 \mu \mathrm{M}\right.$ for 1-48 hr) induces erythrocyte shape changes accompanied by microvesicle (MV) generation. These microvesicles and residual erythrocytes express phosphatidylserine, an important mediator of procoagulant activation. Mercury can provoke procoagulant activity in erythrocytes through protein thiol depletion-mediated phosphatidylserine exposure and MV generation, ultimately leading to enhanced thrombosis [111].

\subsubsection{Molecular Mechanisms of Cardiovascular Mercury} Toxicity. Mercury generates many of its deleterious effects through the formation of free radicals, resulting in DNA damage, lipid peroxidation, depletion of protein sulfhydryls (e.g., glutathione), and other effects [112], which are described below.

(1) Free Radicals. Results from a study with purified cultures of neurons revealed that mitochondria may be the earliest target of methylmercury and that the mitochondrial electron transport chain is the most likely site, where an access of reactive oxygen species is generated in neurons [113]. The levels of antioxidants decrease as an effect of increased free radicals. The exposition to mercuric chloride leads to depletion of the levels of cellular antioxidants including glutathione, vitamin C, and vitamin E [114]. Mercury reduces the antioxidative effect of selenium[115] and the activity of superoxide dismutase and catalase [116, 117].

Free radicals-related markers revealed significant higher level of lipid peroxide, as well as significant lower levels of superoxide dismutase (SOD) activity, catalase activity, and glutathione S-transferase among mercury exposed workers than among controls $(P<0.0001$ for all $)[118]$.

(2) DNA Damage. Experimental data suggest that amalgams, which contain mercury cause an impairment of the cellular pro- and antioxidant redox balance. Mercury trigger the generation of cellular reactive oxygen species, able to cause oxidative DNA lesions. The association between dental fillings and DNA damage is enhanced by the number of fillings and by the exposure time [119].

The effect of mercury on U-937 cells, a human cell line with monocytic characteristics, was studied. The nuclear DNA was damaged, but the cells continued to proliferate when exposed to low doses of mercury between 1 and 5 microM. In higher concentrations, between 1 and 50 microM $\mathrm{Hg}(2+)$, DNA damage and cell death were concentration dependent. This indicates that DNA damage in surviving cells is more sensitive indicator of environmental insult and suggests that low concentrations of ionic mercury may be mutagenic [120].

(3) Lipid Peroxidation. The accumulation of mercury can reduce the bioavailability of selenium and can be one of 
the mechanisms through which mercury promotes lipid peroxidation [87].

It is known from in vitro and in vivo studies that $\mathrm{Hg}$ can promote lipid peroxidation through promotion of free radical generation and interaction with antioxidative enzymes and reduction of bioavailable selenium.

A study of 54 mercury miners of the Idrija Mine/Slovenia and 58 workers as control group indicated that long-term past occupational exposure to elemental $\mathrm{Hg}(\mathrm{Hg} 0)$ can modify antioxidative capacity and promote lipid peroxidation in miners. The miners were examined in the postexposure period. Their previous exposure to $\mathrm{Hg} 0$, the putative appearance of certain nonspecific symptoms, and signs of micromercurialism, as well as the main behavioural and biological risk factors for cardiovascular diseases were evaluated. Furthermore, the following parameters were determined: (a) $\mathrm{Hg}$ and Se levels in blood and urine, (b) antioxidative enzymes, $\mathrm{Cu} / \mathrm{Zn}$ superoxide dismutase, catalase, and selenoenzyme glutathione peroxidase activity in erythrocytes as indirect indices of free radical activity, and (c) pineal hormone melatonin in blood and urine, (d) lipid hydroperoxides and malondialdehyde (MDA) as lipid peroxidation products. Among the observed lipid peroxidative products, the mean concentration of urinary MDA was statistically higher $(P<$ $0.01)$ in miners $(0.21 \mathrm{micromol} / \mathrm{mmol}$ creatinine $)$ than in controls $(0.17 \mathrm{micromol} / \mathrm{mmol}$ creatinine). In the group of miners with high mercury accumulation and the presence of some nonspecific symptoms and signs of micromercurialism, the results of this study partly support the assumption that long-term occupational exposure to $\mathrm{Hg} 0$ enhances the formation of free radicals even several years after termination of occupational exposure long-term occupational exposure to $\mathrm{Hg} 0$ could be one of the risk factors for increased lipid peroxidation and increased mortality due to ischaemic heart disease found among the mercury miners of the Idrija Mine [121].

(4) Endothelial Dysfunction. Oxidative stress is the main cause of the endothelial dysfunction observed in cardiovascular diseases such as hypertension and atherosclerosis. Furthermore, superoxide anion interacts with nitric oxide (NO) and forms peroxynitrite. This mechanism results in the decrease of NO availability for smooth muscle relaxation. Chronic exposure to low concentrations of mercury promotes endothelial dysfunction as a result of the decreased NO bioavailability induced by increases in oxidative stress [122].

(5) Depletion of Protein Sulfhydryls. Mercuric ions have a great affinity to bond to reduced sulphur atoms, especially those on endogenous thiol-containing molecules such as glutathione, cysteine, metallothionein, homocysteine, $\mathrm{N}$-acetylcysteine, and albumin [123]. Therefore, the biological effects of inorganic and organic mercury is related to their interactions with sulfhydryl groups [112]. As elemental mercury, the mercuric mercury in the blood stream binds to sulfhydryl groups on erythrocytes, glutathione, or metallothionein or is transported and suspended in plasma [124].

Depletion of glutathione and protein-bound sulfhydryl groups results in the production of reactive oxygen species as superoxide ion, hydrogen peroxide, and hydroxyl radical. As a consequence, enhanced lipid peroxidation, DNA damage, and altered calcium and sulfhydryl homeostasis occur [125].

In the renal tubules, mercury causes a depletion of glutathione and also a reduction in the activities of superoxide dismutase, catalase, and glutathione peroxidase, enzymes responsible for the protection of cells against the peroxidative action of superoxide anion and hydroperoxides. Thus, nephrotoxicity may be due to mercury-induced alterations in membrane integrity via the formation of reactive oxygen species and the perturbation of antioxidant defense mechanisms $[125,126]$.

(6) Endocrine Disruption. Mercury has been well documented to be an endocrine system disrupting chemical. Mercury accumulates in all hormone glands and adversely affects hormonal function. This includes the disrupting function of the pituitary gland, hypothalamus, and thyroid gland as well as enzyme production processes and many hormonal functions at very low levels of exposure [127]. Mercury has negative effects on the cardiovascular system by inhibiting the enzyme catechol-O-methyltransferase (COMT) through inactivation of its coenzyme S-adenosylmethionine (SAMe). The inhibition of COMT increases serum and urinary epinephrine, norepinephrine, and dopamine. This can cause hypertension, sweating, and tachycardia that may be indistinguishable from pheochromocytoma [128].

\section{Discussion}

Coronary heart disease is called the epidemiology of the 21st century due to its frequency and implication for public health worldwide [129]. The influence of arsenic, lead and, mercury on mortality of CVD is investigated by numerous epidemiological studies in developed as well as in developing countries. They are summarized in several reviews. In addition to the epidemiologic data, molecular studies confirm the role of toxic metals in the development of CVD.

4.1. Arsenic. Chronic arsenic poisoning is an independent risk factor for cardiovascular disease. Epidemiological studies from Taiwan, Bangladesh, India, Argentina, Australia, Chile, China, Hungary, Peru, Thailand, Mexico, and United States of America have shown that chronic arsenic poisoning is often caused through ingestion of arsenic-contaminated water and is associated with various cardiovascular diseases in doseresponse relationships. This includes carotid atherosclerosis detected by ultrasonography, impaired microcirculation, prolonged QT interval, and increased QT dispersion in electrocardiography and clinical outcomes such as hypertension, blackfoot disease, coronary artery disease, and cerebral infarction [130]. Chronic arsenic poisoning inactivates endothelial nitric oxide synthase, leading to reduction in the generation and bioavailability of NO. In addition, the chronic arsenic exposure induces high oxidative stress, which may affect the structure and function of the cardiovascular system. Moreover, arsenic exposure has been noted to induce atherosclerosis by increasing the platelet aggregation and reducing fibrinolysis [52]. 
4.2. Lead. There is a causal relationship of lead exposure with hypertension [57]. Relatively low levels of lead in the blood are associated with cardiovascular outcomes [57]. It is suspected that even small amounts of lead from occupational or environmental exposure, which are stored in bones, result in high blood pressure. In the Third National Health and Nutrition Examination Survey, a direct association between higher blood lead and increased risk of cardiovascular disease, myocardial infarction, and stroke mortality was identified at substantially lower blood lead levels than reported previously [63].

4.3. Mercury. An increased mortality from hypertension and from heart diseases other than ischaemic heart disease was found after long-term exposure to inorganic mercury in mercury miners from Spain, Slovenia, Italy, and Ukraine.

The relationship between mercury and cholesterol level was investigated in a sample of 274 children from three primary schools in South Korea. The urine mercury levels were associated with the serum cholesterol, even with urine mercury concentrations below the suggested level of concern according to the criteria of the Centers for Disease Control (CDC) and ATSDR [88].

Case reports from USA, Germany, and China present children with unexplained tachycardia and hypertension and mercury intoxication. Urinary mercury levels did not correlate in all cases with the severity of clinical signs and symptoms of mercury intoxication, but after diagnosis and chelation the symptoms of all children improved.

Epidemiological studies among Nunavik Inuit adults, a nonindigenous fish-eating population in the Brazilian Amazon, Danes, and Greenlanders showed an increased risk of hypertension correlated with hair and blood mercury levels $[96-98,100]$. Findings from the Faroe Islands suggest that prenatal exposure to methylmercury may affect the development of cardiovascular homeostasis [103].

The Heavy Metals and Myocardial Infarction Study Group indicated in an international case-control study an independent and graded association between toenail mercury levels and the risk of myocardial infarction. The study was conducted in eight European countries and Israel. The first documentation of the association between the accumulation of mercury in the human body and accelerated progression of atherosclerosis, especially carotid atherosclerosis, comes from Finland.

4.4. Molecular Mechanisms. Mercury, arsenic, and lead generates many of their harmful effects through similar molecular mechanisms. These include formation of free radicals, resulting in decreased NO bioavailability, lipid peroxidation, DNA damage, decreased levels of antioxidants, depletion of protein sulfhydryls (e.g., glutathione), and other effects. This induces functional and morphologic changes in the endothelium leading to endothelial dysfunction which is the beginning of the fibrous change of arterial vascular walls and atherosclerosis.

The harmful effects of arsenic, lead, and mercury are based to a large part on the same pathological mechanism.
Combined metal interactions as a risk factor for CVD are not investigated, but the role of metals in carcinogenesis and how concomitant exposure to metal mixtures can influence cancer induction is reviewed in 2003. Exposures to complex metal mixtures can enhance the risk of cancer in certain human populations. The findings of the review show that combined metal interactions are more important than the sum of the individual metal effects [131]. Combined with mercury or cadmium no observed effect Level (NOEL) dose of lead showed toxicity, indicating that exposure limits may be inefficient in combined exposure situations [132]. Results from the investigation of metal interactions indicate that in addition to the effects of arsenic, lead, and mercury as single toxins combined metal interactions of these potential toxic metals should be considered as a risk factor for the development of CVD.

\section{Conclusion}

The major risk factors for CVD are identified by the Framingham Heart Study (FHS). Beyond the FHS, numerous studies indicate a correlation between environmental pollution and the development of CVD. By following the CERCLA Priority List published by the ATSDR and EPA, arsenic, lead, and mercury are the most hazardous substances. Their effects on the cardiovascular system are founded on the endothelial dysfunction caused by stimulation of ROS, decrease of levels of antioxidants, inhibition of endothelial NO synthesis, enhanced lipid peroxidation, inhibitory effects on the mitochondrial respiratory chain, endothelial cell proliferation, apoptosis and DNA damage. The effects of chronic low-dose exposure to arsenic, lead, and mercury result in high blood pressure, arrhythmia, accelerated progression of atherosclerosis, enhanced carotid sclerosis, elevated risk of myocardial infarction, and an increased mortality from cardiovascular diseases.

Chronic arsenic poisoning as well as chronic lead and mercury poisoning is an independent risk factor for cardiovascular disease. Intensified research showed that the limit values for the vascular- and blood pressure-damaging effect of these most hazardous substances had repetitively to be corrected downward. Combined metal interactions should be considered a risk factor for the development of CVD. Because CVD is the leading cause of death worldwide the efforts of the national health care systems in identifying the risk factors for cardiovascular diseases and the development of new strategies for prevention and treatment must be lit up. Prevention, diagnosis, and treatment of occupational and environmental exposures to arsenic, lead, and mercury should be integrated in the guidelines for CVD.

\section{Conflict of Interest}

The author declare that there is no conflict of interests. 


\section{References}

[1] P. Rösen, "Endothelial dysfunction: a synonym for functional atherosclerosis," Journal fur Kardiologie, vol. 9, no. 12, pp. 556-562, 2002.

[2] J. A. Suwaidi, S. Hamasaki, S. T. Higano, R. A. Nishimura, D. R. Holmes, and A. Lerman, "Long-term follow-up of patients with mild coronary artery disease and endothelial dysfunction," Circulation, vol. 101, no. 9, pp. 948-954, 2000.

[3] V. Schächinger, M. B. Britten, and A. M. Zeiher, "Prognostic impact of coronary vasodilator dysfunction on adverse longterm outcome of coronary heart disease," Circulation, vol. 101, no. 16, pp. 1899-1906, 2000.

[4] Statistisches Bundesamt, Wirtschaft und Statistik, p. 891, 2010.

[5] M. P. Heron, D. L. Hoyert, S. L. Murphy, J. Q. Xu, K. D. Kochanek, and B. Tejada-Vera, "Deaths: final data for 2006," National Vital Statistics Reports, vol. 57, no. 14, pp. 1-134, 2009.

[6] D. Lloyd-Jones, R. Adams, M. Carnethon et al., "Heart disease and stroke statistics-2009 update: a report from the American Heart Association Statistics Committee and Stroke Statistics Subcommittee," Circulation, vol. 119, no. 3, pp. 480-486, 2009.

[7] World Health Organization, The Global Burden of Disease, 2004.

[8] R. B. D’Agostino, R. S. Vasan, M. J. Pencina et al., “General cardiovascular risk profile for use in primary care: the Framingham heart study," Circulation, vol. 117, no. 6, pp. 743-753, 2008.

[9] B. Weinhold, "Environmental cardiology: getting to the heart of the matter," Environmental Health Perspectives, vol. 112, no. 15, pp. A880-A887, 2004.

[10] A. Bhatnagar, "Environmental cardiology: studying mechanistic links between pollution and heart disease," Circulation Research, vol. 99, no. 7, pp. 692-705, 2006.

[11] CERCLA Priority List of Hazardous Substances, 2012, http://www.atsdr.cdc.gov/SPL/index.html.

[12] “Toxicological Profile For Arsenic," 2012, http://www.atsdr .cdc.gov/ToxProfiles/tp2.pdf.

[13] J. St Petery, C. Gross, and B. E. Victorica, "Ventricular fibrillation caused by arsenic poisoning," American Journal of Diseases of Children, vol. 120, no. 4, pp. 367-371, 1970.

[14] J. C. Hall and R. Harruff, "Fatal cardiac arrhythmia in a patient with interstitial myocarditis related to chronic arsenic poisoning," Southern Medical Journal, vol. 82, no. 12, pp. 1557-1560, 1989.

[15] R. E. Little, G. N. Kay, J. B. Cavender, A. E. Epstein, and V. J. Plumb, "Torsade de pointes and T-U wave alternans associated with arsenic poisoning," Pacing and Clinical Electrophysiology, vol. 13, no. 2, pp. 164-170, 1990.

[16] J. L. Mumford, K. Wu, Y. Xia et al., "Chronic arsenic exposure and cardiac repolarization abnormalities with QT interval prolongation in a population-based study," Environmental Health Perspectives, vol. 115, no. 5, pp. 690-694, 2007.

[17] P. Westervelt, R. A. Brown, D. R. Adkins et al., "Sudden death among patients with acute promyelocytic leukemia treated with arsenic trioxide," Blood, vol. 98, no. 2, pp. 266-271, 2001.

[18] A. Navas-Acien, A. R. Sharrett, E. K. Silbergeld et al., "Arsenic exposure and cardiovascular disease: a systematic review of the epidemiologic evidence," American Journal of Epidemiology, vol. 162, no. 11, pp. 1037-1049, 2005.
[19] L. Geyer, "Ueber die chronischen Hautveränderungen beim Arsenicismus und Betrachtungen über die Massenerkrankungen in Reichenstein in Schlesien," Archiv für Dermatologie und Syphilis, vol. 43, no. 1, pp. 221-280, 1898.

[20] K. H. Butzengeiger, "Über Periphere Zirkulationsstörungen bei Chronischer Arsenvergiftung," Klinische Wochenschrift, vol. 19, no. 22, pp. 523-527, 1940.

[21] W. P. Tseng, "Effects and dose response relationships of skin cancer and blackfoot disease with arsenic," Environmental Health Perspectives, vol. 19, pp. 109-119, 1977.

[22] W. P. Tseng, "Blackfoot disease in Taiwan: a 30-year follow-up study," Angiology, vol. 40, no. 6, pp. 547-558, 1989.

[23] C. H. Wang, J. S. Jeng, P. K. Yip et al., "Biological gradient between long-term arsenic exposure and carotid atherosclerosis," Circulation, vol. 105, no. 15, pp. 1804-1809, 2002.

[24] R. Zaldivar and A. Guillier, "Environmental and clinical investigations on endemic chronic arsenic poisoning in infants and children," Zentralblatt fur Bakteriologie B, vol. 165, no. 2, pp. 226-234, 1977.

[25] H. G. Rosenberg, "Systemic arterial disease and chronic arsenicism in infants," Archives of Pathology and Laboratory Medicine, vol. 97, no. 6, pp. 360-365, 1974.

[26] C. H. Tseng, C. K. Chong, C. J. Chen, B. J. Lin, and T. Y. Tai, "Abnormal peripheral microcirculation in seemingly normal subjects living in blackfoot-disease-hyperendemic villages in Taiwan," International Journal of Microcirculation, Clinical and Experimental, vol. 15, no. 1, pp. 21-27, 1995.

[27] Y. Chen and H. Ahsan, "Cancer burden from arsenic in drinking water in Bangladesh," American Journal of Public Health, vol. 94, no. 5, pp. 741-744, 2004.

[28] Y. Chen, J. H. Graziano, F. Parvez et al., "Arsenic exposure from drinking water and mortality from cardiovascular disease in Bangladesh: prospective cohort study," British Medical Journal, vol. 342, no. 7806, 2011.

[29] Y. Yuan, G. Marshall, C. Ferreccio et al., "Acute myocardial infarction mortality in comparison with lung and bladder cancer mortality in arsenic-exposed region II of Chile from 1950 to 2000," American Journal of Epidemiology, vol. 166, no. 12, pp. 1381-1391, 2007.

[30] S. L. Wang, J. M. Chiou, C. J. Chen et al., "Prevalence of non-insulin-dependent diabetes mellitus and related vascular diseases in southwestern arseniasis-endemic and nonendemic areas in Taiwan," Environmental Health Perspectives, vol. 111, no. 2, pp. 155-159, 2003.

[31] WHO, "Environmental Health Criteria, Arsenic," pp 1-174. World Health Organization, Geneva, Switzerland, 1981.

[32] WHO, "Environmental Health Criteria 224: Arsenic and Arsenic Compounds," 2nd ed, pp 385-392, World Health Organization, Geneva, Switzerland, 2001.

[33] J. Pi, Y. Kumagai, G. Sun et al., "Decreased serum concentrations of nitric oxide metabolites among Chinese in an endemic area of chronic arsenic poisoning in inner Mongolia," Free Radical Biology and Medicine, vol. 28, no. 7, pp. 1137-1142, 2000.

[34] Y. Kumagai and J. Pi, "Molecular basis for arsenic-induced alteration in nitric oxide production and oxidative stress: implication of endothelial dysfunction," Toxicology and Applied Pharmacology, vol. 198, no. 3, pp. 450-457, 2004. 
[35] M. Y. Lee, B. I. Jung, S. M. Chung et al., "Arsenic-induced dysfunction in relaxation of blood vessels," Environmental Health Perspectives, vol. 111, no. 4, pp. 513-517, 2003.

[36] M. Bunderson, J. D. Coffin, and H. D. Beall, "Arsenic induces peroxynitrite generation and cyclooxygenase- 2 protein expression in aortic endothelial cells: possible role in atherosclerosis," Toxicology and Applied Pharmacology, vol. 184, no. 1, pp. 11-18, 2002.

[37] J. Hakim, "Reactive oxygen species and inflammation," Comptes Rendus des Séances de la Société de Biologie et de ses Filiales, vol. 187, no. 3, pp. 286-295, 1993.

[38] G. Kojda and D. Harrison, "Interactions between NO and reactive oxygen species: pathophysiological importance in atherosclerosis, hypertension, diabetes and heart failure," Cardiovascular Research, vol. 43, no. 3, pp. 562-571, 1999.

[39] A. L. Luna, L. C. Acosta-Saavedra, L. Lopez-Carrillo et al., "Arsenic alters monocyte superoxide anion and nitric oxide production in environmentally exposed children," Toxicology and Applied Pharmacology, vol. 245, no. 2, pp. 244-251, 2010.

[40] T. S. Wang, C. F. Kuo, K. Y. Jan et al., "Arsenite induces apoptosis in Chinese hamster ovary cells by generation of reactive oxygen species," Journal of Cellular Physiology, vol. 169, pp. 256-268, 1996.

[41] M. M. Wu, H. Y. Chiou, T. W. Wang et al., "Association of blood arsenic levels with increased reactive oxidants and decreased antioxidant capacity in a human population of Northeastern Taiwan," Environmental Health Perspectives, vol. 109, no. 10, pp. 1011-1017, 2001.

[42] A. Y. Andreyev, Y. E. Kushnareva, and A. A. Starkov, "Mitochondrial metabolism of reactive oxygen species," Biokhimiya, vol. 70, no. 2, pp. 246-264, 2005.

[43] L. Packer, "Metabolic and structural states of mitochondria. II. Regulation by phosphate," The Journal of Biological Chemistry, vol. 236, pp. 214-220, 1961.

[44] B. Chen, C. T. Burt, P. L. Goering, B. A. Fowler, and R. E. London, "In vivo 31P nuclear magnetic resonance studies of arsenite induced changes in hepatic phosphate levels," Biochemical and Biophysical Research Communications, vol. 139, no. 1, pp. 228-234, 1986.

[45] K. V. Chin, S. Tanaka, G. Darlington, I. Pastan, and M. M. Gottesman, "Heat shock and arsenite increase expression of the multidrug resistance (MDR1) gene in human renal carcinoma cells," The Journal of Biological Chemistry, vol. 265, no. 1, pp. 221-226, 1990.

[46] J. Pi, H. Yamauchi, Y. Kumagai et al., "Evidence for induction of oxidative stress caused by chronic exposure of Chinese residents to arsenic contained in drinking water," Environmental Health Perspectives, vol. 110, no. 4, pp. 331-336, 2002.

[47] Y. H. Liao, L. C. Hwang, J. S. Kao et al., "Lipid peroxidation in workers exposed to aluminium, gallium, indium, arsenic, and antimony in the optoelectronic industry," Journal of Occupational and Environmental Medicine, vol. 48, no. 8, pp. 789-793, 2006.

[48] R. Chowdhury, R. Chatterjee, A. K. Giri, C. Mandal, and K. Chaudhuri, "Arsenic-induced cell proliferation is associated with enhanced ROS generation, Erk signaling and CyclinA expression," Toxicology Letters, vol. 198, no. 2, pp. 263-271, 2010.
[49] Y. C. Chen, S. Y. Lin-Shiau, and J. K. Lin, "Involvement of reactive oxygen species and caspase 3 activation in arseniteinduced apoptosis," Journal of Cellular Physiology, vol. 177, pp. 324-333, 1998.

[50] H. Ohkawara, T. Ishibashi, K. Ando et al., "Akt cooperates with membrane type 1-matrix metalloproteinase (MT1-MMP) in TNF-alpha-induced signaling pathways of endothelial dysfunction and haemostasis," Circulation, vol. 120, pp. S1029-S1030, 2009.

[51] P. Balakumar and J. Kaur, "Arsenic exposure and cardiovascular disorders: an overview," Cardiovascular Toxicology, vol. 9, no. 4, pp. 169-176, 2009.

[52] M. Y. Lee, O. N. Bae, S. M. Chung et al., "Enhancement of platelet aggregation and thrombus formation by arsenic in drinking water: a contributing factor to cardiovascular disease," Toxicology and Applied Pharmacology, vol. 179, no. 2, pp. 83-88, 2002.

[53] M. L. Kile, E. A. Houseman, E. Rodrigues et al., "Polymorphisms, and arsenic exposure from drinking water toenail arsenic concentrations, GSTT1 gene," Cancer Epidemiology, Biomarkers \& Prevention, vol. 14, no. 10, pp. 2419-2426, 2005.

[54] J. C. States, S. Srivastava, Y. Chen, and A. Barchowsky, "Arsenic and cardiovascular disease," Toxicological Sciences, vol. 107, no. 2, pp. 312-323, 2009.

[55] Y. C. Hsieh, F. I. Hsieh, L. M. Lien, Y. L. Chou, H. Y. Chiou, and C. J. Chen, "A significantly age- and gender-adjusted odds ratio of 2.0 for the development of carotid atherosclerosis was observed in study subjects with epsilon4 allele of APOE than those without epsilon4 allele," Toxicology and Applied Pharmacology, vol. 227, no. 1, pp. 1-7, 2008.

[56] Department of Ecology State of Washington, "Lead Poisoning," http://www.ecy.wa.gov/programs/hwtr/dangermat/lead.html.

[57] A. Navas-Acien, E. Guallar, E. K. Silbergeld, and S. J. Rothenberg, "Lead exposure and cardiovascular disease - a systematic review," Environmental Health Perspectives, vol. 115, no. 3, pp. 472-482, 2007.

[58] D. Nash, L. Magder, M. Lustberg et al., "Blood lead, blood pressure, and hypertension in perimenopausal and postmenopausal women," Journal of the American Medical Association, vol. 289, no. 12, pp. 1523-1532, 2003.

[59] S. W. Tsaih, S. Korrick, J. Schwartz et al., "Influence of bone resorption on the mobilization of lead from bone among middle-aged and elderly men: the normative aging study," Environmental Health Perspectives, vol. 109, no. 10, pp. 995-999, 2001.

[60] C. Yazbeck, O. Thiebaugeorges, T. Moreau et al., "Maternal blood lead levels and the risk of pregnancy-induced hypertension: the EDEN cohort study," Environmental Health Perspectives, vol. 117, no. 10, pp. 1526-1530, 2009.

[61] S. Skerfving, "Criteria Document for Swedish Occupational Standards. Inorganic lead-an update 1991-2004," 2005, http://ebib.arbetslivsinstitutet.se/ah/2005/ah2005_03.pdf.

[62] M. Lustberg and E. Silbergeld, "Blood lead levels and mortality," Archives of Internal Medicine, vol. 162, no. 21, pp. 2443-2449, 2002.

[63] A. Menke, P. Muntner, V. Batuman, E. K. Silbergeld, and E. Guallar, "Blood lead below $0.48 \mu \mathrm{mol} / \mathrm{L}(10 \mu \mathrm{g} / \mathrm{dL})$ and mortality among US adults," Circulation, vol. 114, no. 13, pp. 1388-1394, 2006. 
[64] L. Moller and T. S. Kristensen, "Blood lead as a cardiovascular risk factor," American Journal of Epidemiology, vol. 136, no. 9, pp. 1091-1100, 1992.

[65] R. A. Goyer, "Lead and the kidney," Current Topics in Pathology, vol. 55, pp. 147-176, 1971.

[66] J. J. Chisolm and N. B. Leahy, "Aminoaciduria as a manifestation of renal tubular injury in lead intoxication and a comparison with patterns of aminoaciduria seen in other diseases," The Journal of Pediatrics, vol. 60, no. 1, pp. 1-17, 1962.

[67] K. Cramér, R. A. Goyer, R. Jagenburg et al., "Renal ultrastructure, renal function, and parameters of lead toxicity in workers with different periods of lead exposure," British Journal of Industrial Medicine, vol. 31, no. 2, pp. 113-127, 1974.

[68] J. A. Staessen, R. R. Lauwerys, J.-P. Buchet et al., "Impairment of renal function with increasing blood lead concentrations in the general population," The New England Journal of Medicine, vol. 327, no. 3, pp. 151-156, 1992.

[69] V. Batuman, E. Landy, J. K. Maesaka, and R. P. Wedeen, "Contribution of lead to hypertension with renal impairment," The New England Journal of Medicine, vol. 309, no. 1, pp. 17-21, 1983.

[70] P. C. Hsu and Y. L. Guo, "Antioxidant nutrients and lead toxicity," Toxicology, vol. 180, no. 1, pp. 33-44, 2002.

[71] L. Patrick, "Lead toxicity part II: the role of free radical damage and the use of antioxidants in the pathology and treatment of lead toxicity," Alternative Medicine Review, vol. 11, no. 2, pp. 114-127, 2006

[72] N. T. Christie and M. Costa, "In vitro assessment of the toxicity of metal compounds. IV. Disposition of metals in cells: Interactions with membranes, glutathione, metallothionein, and DNA," Biological Trace Element Research, vol. 6, no. 2, pp. 139-158, 1984

[73] M. Ahamed, S. Verma, A. Kumar, and M. K. J. Siddiqui, "Environmental exposure to lead and its correlation with biochemical indices in children," Science of the Total Environment, vol. 346, no. 1-3, pp. 48-55, 2005.

[74] G. Garçon, B. Leleu, F. Zerimech et al., "Biologic markers of oxidative stress and nephrotoxicity as studied in biomonitoring of adverse effects of occupational exposure to lead and cadmium," Journal of Occupational and Environmental Medicine, vol. 46, no. 11, pp. 1180-1186, 2004.

[75] A. Hunaiti, M. Soud, and A. Khalil, "Lead concentration and the level of glutathione, glutathione S-transferase, reductase and peroxidase in the blood of some occupational workers from Irbid City, Jordan," Science of the Total Environment, vol. 170, no. 1-2, pp. 95-100, 1995.

[76] R. Sandhir, D. Julka, and K. D. Gill, "Lipoperoxidative damage on lead exposure in rat brain and its implications on membrane bound enzymes," Pharmacology and Toxicology, vol. 74, no. 2, pp. 66-71, 1994.

[77] M. Kuzuya, M. Naito, C. Funaki, T. Hayashi, K. Asai, and F. Kuzuya, "Protective role of intracellular glutathione against oxidized low density lipoprotein in cultured endothelial cells," Biochemical and Biophysical Research Communications, vol. 163, no. 3, pp. 1466-1472, 1989.

[78] H. Gurer and N. Ercal, "Can antioxidants be beneficial in the treatment of lead poisoning?" Free Radical Biology and Medicine, vol. 29, no. 10, pp. 927-945, 2000.
[79] G. J. S. Flora and P. K. Seth, "Alterations in some membrane properties in rat brain following exposure to lead," Cytobios, vol. 2000, no. 403, pp. 103-109, 2000.

[80] S. R. Ribarov and L. C. Benov, "Relationship between the hemolytic action of heavy metals and lipid peroxidation," Biochimica et Biophysica Acta, vol. 640, no. 3, pp. 721-726, 1981.

[81] N. D. Vaziri, F. Oveisi, and Y. Ding, "Role of increased oxygen free radical activity in the pathogenesis of uremic hypertension," Kidney International, vol. 53, no. 6, pp. 1748-1754, 1998.

[82] B. Halliwell, "What nitrates tyrosine? Is nitrotyrosine specific as a biomarker of peroxynitrite formation in vivo," FEBS Letters, vol. 411 , no. $2-3$, pp. 157-160, 1997.

[83] N. D. Vaziri, Y. Ding, Z. Ni, and H. C. Gonick, "Altered nitric oxide metabolism and increased oxygen free radical activity in lead-induced hypertension: effect of lazaroid therapy," Kidney International, vol. 52, no. 4, pp. 1042-1046, 1997.

[84] P. Apostoli, A. Corulli, M. Metra, and L. Dei Cas, "Lead and heart disease," Medicina del Lavoro, vol. 95, no. 2, pp. 124-132, 2004.

[85] D. A. Tsao, H. S. Yu, J. T. Cheng, C. K. Ho, and H. R. Chang, "The change of beta-adrenergic system in lead-induced hypertension," Toxicology and Applied Pharmacology, vol. 164, no. 2, pp. 127-133, 2000.

[86] T. W. Clarkson and L. Magos, "The toxicology of mercury and its chemical compounds," Critical Reviews in Toxicology, vol. 36, no. 8, pp. 609-662, 2006.

[87] P. Boffetta, G. Sällsten, M. Garcia-Gómez et al., "Mortality from cardiovascular diseases and exposure to inorganic mercury," Occupational and Environmental Medicine, vol. 58, no. 7, pp. 461-466, 2001.

[88] D. S. Kim, E. H. Lee, S. D. Yu et al., "Heavy metal as risk factor of cardiovascular disease-an analysis of blood lead and urinary mercury," Journal of Preventive Medicine and Public Health, vol. 38, no. 4, pp. 401-407, 2005.

[89] International Programme on Chemical Safety (IPCS), Environmental Health Criteria 101. Methylmercury, World Health Organization, Geneva, Switzerland, 1990.

[90] W. Wossmann, M. Kohl, G. Grüning, and P. Bucsky, "Mercury intoxication presenting with hypertension and tachycardia," Archives of Disease in Childhood, vol. 80, no. 6, pp. 556-557, 1999.

[91] X. Z. Chang, H. M. Lu, and Y. H. Zhang, "Hypertension and erythromelalgia as prominent manifestations of mercury intoxication," Beijing Da Xue Xue Bao, vol. 39, no. 4, pp. 377-380, 2007.

[92] A. D. Torres, A. N. Rai, and M. L. Hardiek, "Mercury intoxication and arterial hypertension: report of two patients and review of the literature," Pediatrics, vol. 105, no. 3, p. E34, 2000.

[93] J. Gattineni, S. Weiser, A. M. Becker, and M. Baum, "Mercury intoxication: lack of correlation between symptoms and levels," Clinical Pediatrics, vol. 46, no. 9, pp. 844-846, 2007.

[94] C. Henningsson, S. Hoffmann, L. McGonigle, and J. S. D. Winter, "Acute mercury poisoning (acrodynia) mimicking pheochromocytoma in an adolescent," Journal of Pediatrics, vol. 122, no. 2, pp. 252-253, 1993.

[95] R. B. McFee and T. R. Caraccio, "Intravenous mercury injection and ingestion: clinical manifestations and management," Journal of Toxicology, vol. 39, no. 7, pp. 733-738, 2001. 
[96] B. Valera, E. Dewailly, and P. Poirier, "Cardiac autonomic activity and blood pressure among Nunavik Inuit adults exposed to environmental mercury: a cross-sectional study," Environmental Health, vol. 7, article 29, 2008.

[97] B. Valera, E. Dewailly, and P. Poirier, "Environmental mercury exposure and blood pressure among Nunavik inuit adults," Hypertension, vol. 54, no. 5, pp. 981-986, 2009.

[98] M. Fillion, D. Mergler, C. J. Sousa Passos, F. Larribe, M. Lemire, and J. R. D. Guimarães, "A preliminary study of mercury exposure and blood pressure in the Brazilian Amazon," Environmental Health, vol. 5, article 29, 2006.

[99] L. E. Bautista, J. H. Stein, B. J. Morgan, N. Stanton, T. Young, and F. J. Nieto, "Association of blood and hair mercury with blood pressure and vascular reactivity," Wisconsin Medical Journal, vol. 108, no. 5, pp. 250-252, 2009.

[100] E. B. Pedersen, M. E. Jørgensen, M. B. Pedersen et al., "Relationship between mercury in blood and 24-h ambulatory blood pressure in greenlanders and Danes," American Journal of Hypertension, vol. 18, no. 5, part 1, pp. 612-618, 2005.

[101] R. L. Siblerud, “The relationship between mercury from dental amalgam and the cardiovascular system," Science of the Total Environment, vol. 99, no. 1-2, pp. 23-35, 1990.

[102] J. Joaquim de Oliveira and S. R. Silva, "Arterial hypertension due to mercury intoxication with clinico-laboratorial syndrome simulating pheochromocytoma," Arquivos Brasileiros de Cardiologia, vol. 66, no. 1, pp. 29-31, 1996.

[103] N. Sørensen, K. Murata, E. Budtz-Jørgensen, P. Weihe, and P. Grandjean, "Prenatal methylmercury exposure as a cardiovascular risk factor at seven years of age," Epidemiology, vol. 10, no. 4, pp. 370-375, 1999.

[104] J. T. Salonen, K. Seppanen, K. Nyyssonen et al., "Intake of mercury from fish, lipid peroxidation, and the risk of myocardial infarction and coronary, cardiovascular, and any death in Eastern Finnish men," Circulation, vol. 91, no. 3, pp. 645-655, 1995.

[105] J. T. Salonen, K. Seppänen, T. A. Lakka, R. Salonen, and G. A. Kaplan, "Mercury accumulation and accelerated progression of carotid atherosclerosis: a population-based prospective 4-year follow-up study in men in eastern Finland," Atherosclerosis, vol. 148, no. 2, pp. 265-273, 2000.

[106] A. Skoczyńska, R. Por冈ba, A. Steinmentz-Beck et al., “The dependence between urinary mercury concentration and carotid arterial intima-media thickness in workers occupationally exposed to mercury vapour," International Journal of Occupational Medicine and Environmental Health, vol. 22, no. 2, pp. 135-142, 2009.

[107] E. Guallar, M. I. Sanz-Gallardo, P. van’t Veer et al., "Mercury, fish oils, and the risk of myocardial infarction," The New England Journal of Medicine, vol. 347, no. 22, pp. 1747-1754, 2002.

[108] J. K. Virtanen, S. Voutilainen, T. H. Rissanen et al., "Mercury, fish oils, and risk of acute coronary events and cardiovascular disease, coronary heart disease, and all-cause mortality in men in Eastern Finland," Arteriosclerosis, Thrombosis, and Vascular Biology, vol. 25, no. 1, pp. 228-233, 2005.

[109] A. Skoczynska, M. Jedrejko, H. Martynowicz et al., "The cardiovascular risk in chemical factory workers exposed to mercury vapor," Medycyna Pracy, vol. 61, no. 4, pp. 381-391, 2010.
[110] D. E. Macfarlane, “The effects of methyl mercury on platelets. Induction of aggregation and release via activation of the prostaglandin synthesis pathway," Molecular Pharmacology, vol. 19, no. 3, pp. 470-476, 1981.

[111] K. M. Lim, S. Kim, J. Y. Noh et al., "Low-level mercury can enhance procoagulant activity of erythrocytes: a new contributing factor for mercury-related thrombotic disease," Environmental Health Perspectives, vol. 118, no. 7, pp. 928-935, 2010.

[112] M. Valko, H. Morris, and M. T. D. Cronin, "Metals, toxicity and oxidative stress," Current Medicinal Chemistry, vol. 12, no. 10, pp. 1161-1208, 2005.

[113] S. Yee and B. H. Choi, "Oxidative stress in neurotoxic effects of methylmercury poisoning," NeuroToxicology, vol. 17, no. 1, pp. 17-26, 1996.

[114] H. Fukino, M. Hirai, Y. M. Hsueh, and Y. Yamane, "Effect of zinc pretreatment on mercuric chloride-induced lipid peroxidation in the rat kidney," Toxicology and Applied Pharmacology, vol. 73, no. 3, pp. 395-401, 1984.

[115] H. E. Ganther, C. Goudie, M. L. Sunde et al., "Selenium: relation to decreased toxicity of methylmercury added to diets containing tuna," Science, vol. 175, no. 4026, pp. 1122-1124, 1972.

[116] L. C. Benov, I. C. Benchev, and O. H. Monovich, "Thiol antidotes effect on lipid peroxidation in mercury-poisoned rats," Chemico-Biological Interactions, vol. 76, no. 3, pp. 321-332, 1990.

[117] P. Bulat, I. Dujić, B. Potkonjak, and A. Vidaković, "Activity of glutathione peroxidase and superoxide dismutase in workers occupationally exposed to mercury," International Archives of Occupational and Environmental Health, vol. 71, supplement, pp. S37-S39, 1998.

[118] H. A. Abdel-Hamid, F. C. Fahmy, and I. A. Sharaf, "Influence of free radicals on cardiovascular risk due to occupational exposure to mercury," The Journal of the Egyptian Public Health Association, vol. 76, no. 1-2, pp. 53-69, 2001.

[119] A. Di Pietro, G. Visalli, S. La Maestra et al., "Biomonitoring of DNA damage in peripheral blood lymphocytes of subjects with dental restorative fillings," Mutation Research, vol. 650, no. 2, pp. 115-122, 2008.

[120] E. Y. Ben-Ozer, A. J. Rosenspire, M. J. McCabe et al., "Mercuric chloride damages cellular DNA by a non-apoptotic mechanism," Mutation Research, vol. 470, no. 1, pp. 19-27, 2000.

[121] A. B. Kobal, M. Horvat, M. Prezelj et al., "The impact of long-term past exposure to elemental mercury on antioxidative capacity and lipid peroxidation in mercury miners," Journal of Trace Elements in Medicine and Biology, vol. 17, no. 4, pp. 261-274, 2004.

[122] G. A. Wiggers, F. M. Peçanha, A. M. Briones et al., "Low mercury concentrations cause oxidative stress and endothelial dysfunction in conductance and resistance arteries," American Journal of Physiology, vol. 295, no. 3, pp. H1033-H1043, 2008.

[123] B. Hultberg, A. Andersson, and A. Isaksson, "Interaction of metals and thiols in cell damage and glutathione distribution: potentiation of mercury toxicity by dithiothreitol," Toxicology, vol. 156, no. 2-3, pp. 93-100, 2001.

[124] N. Ballatori and T. W. Clarkson, "Biliary secretion of glutathione and of glutathione-metal complexes," Fundamental and Applied Toxicology, vol. 5, no. 5, pp. 816-831, 1985. 
[125] S. J. Stohs and D. Bagchi, "Oxidative mechanisms in the toxicity of metal ions," Free Radical Biology and Medicine, vol. 18, no. 2, pp. 321-336, 1995.

[126] G. Gstraunthaler, W. Pfaller, and P. Kotanko, "Glutathione depletion and in vitro lipid peroxidation in mercury or maleate induced acute renal failure," Biochemical Pharmacology, vol. 32, no. 19, pp. 2969-2972, 1983.

[127] B. Windham, "Mercury Exposure Levels from Amalgam Dental fillings; Documentation of Mechanisms by which Mercury causes over 40 Chronic Health Conditions, Results of Replacement of Amalgam fillings, and Occupational Effects on Dental Staff," 2002, http://www.fda.gov/ohrms/dockets/dailys/ 02/\%20Sep02/091602/80027dde.pdf.

[128] “International Programme on Chemical Safety," Mercury, inorganic, WHO, Geneva, Switzerland, Environmental Health Criteria no. 118, 1991.

[129] H. A. Tyroler, "Coronary heart disease epidemiology in the 21st century," Epidemiologic Reviews, vol. 22, no. 1, pp. 7-13, 2000.

[130] C. H. Wang, C. K. Hsiao, C. L. Chen et al., "A review of the epidemiologic literature on the role of environmental arsenic exposure and cardiovascular diseases," Toxicology and Applied Pharmacology, vol. 222, no. 3, pp. 315-326, 2007.

[131] E. F. Madden, “The role of combined metal interactions in metal carcinogenesis: a review," Reviews on Environmental Health, vol. 18, no. 2, pp. 91-109, 2003.

[132] L. Institoris, D. Kovacs, I. Kecskemeti-Kovacs et al., "Immunotoxicological investigation of subacute combined exposure with low doses of $\mathrm{Pb}, \mathrm{Hg}$ and $\mathrm{Cd}$ in rats," Acta Biologica Hungarica, vol. 57, no. 4, pp. 433-439, 2006. 


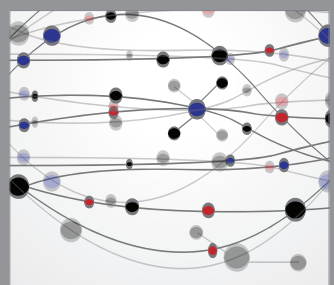

The Scientific World Journal
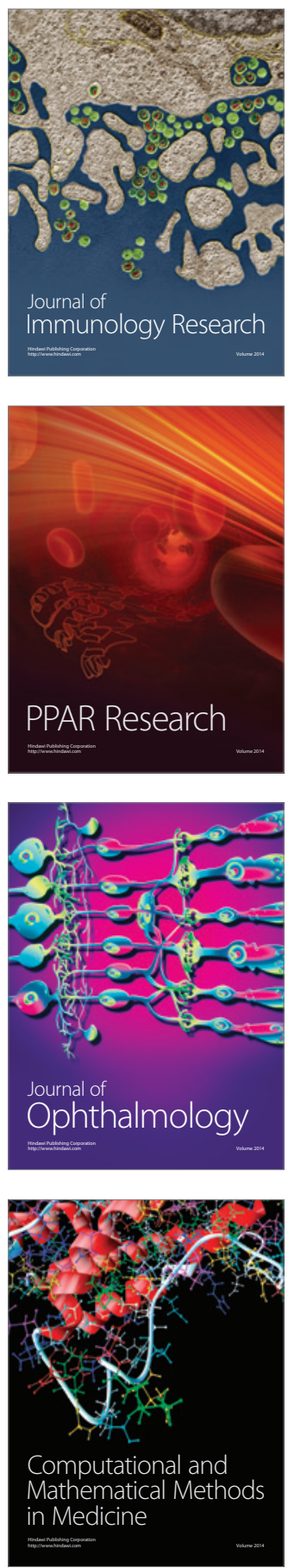

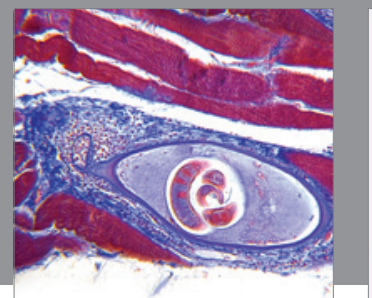

Gastroenterology

Research and Practice
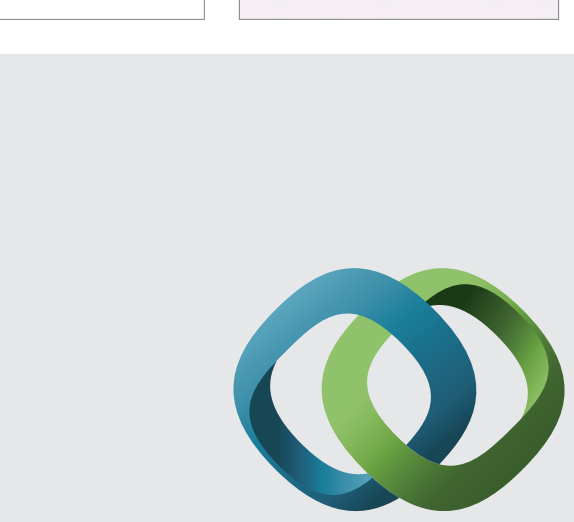

\section{Hindawi}

Submit your manuscripts at

http://www.hindawi.com
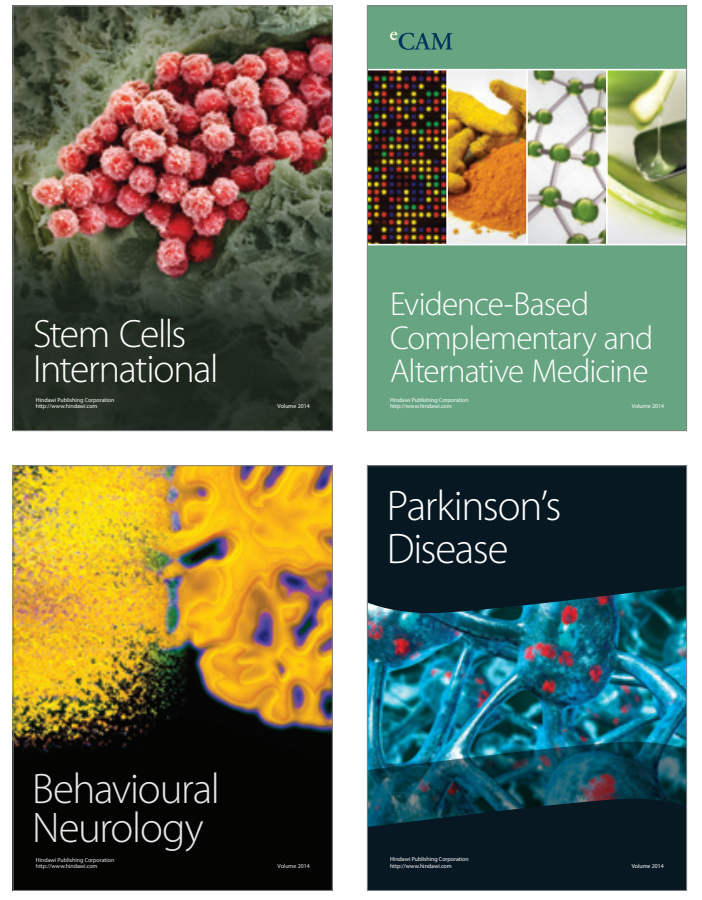
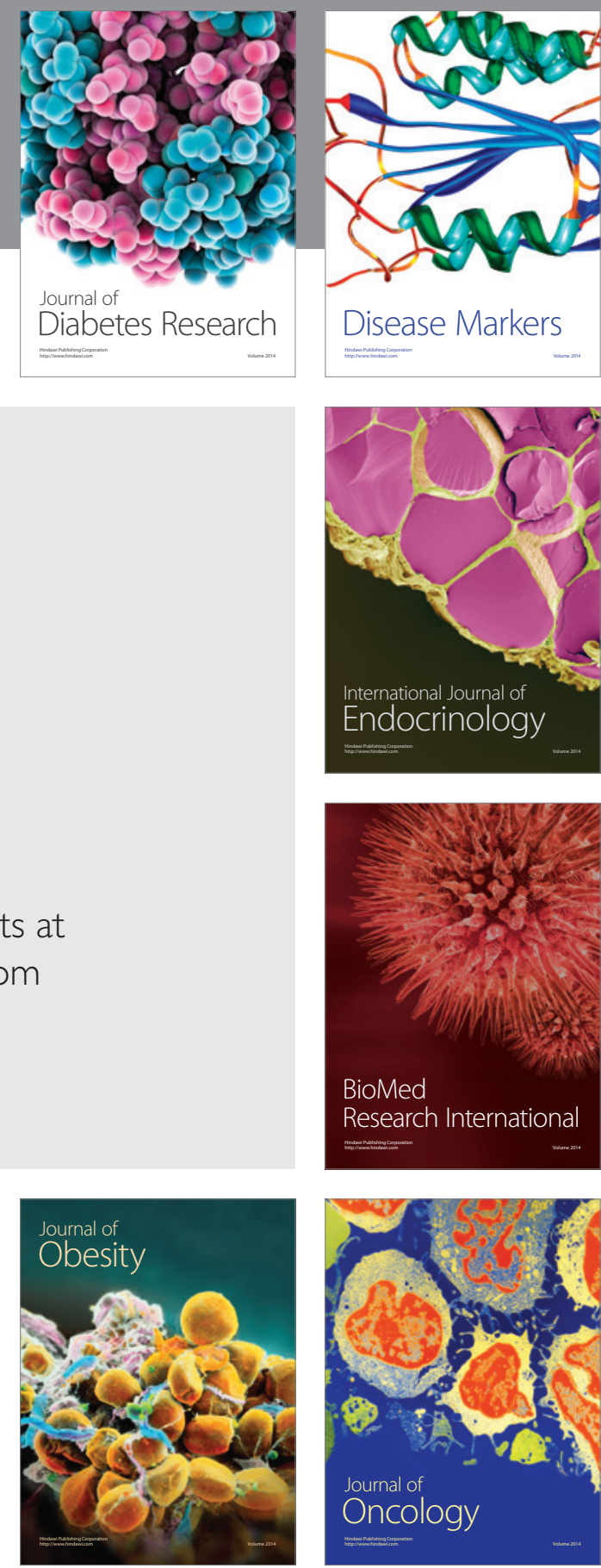

Disease Markers
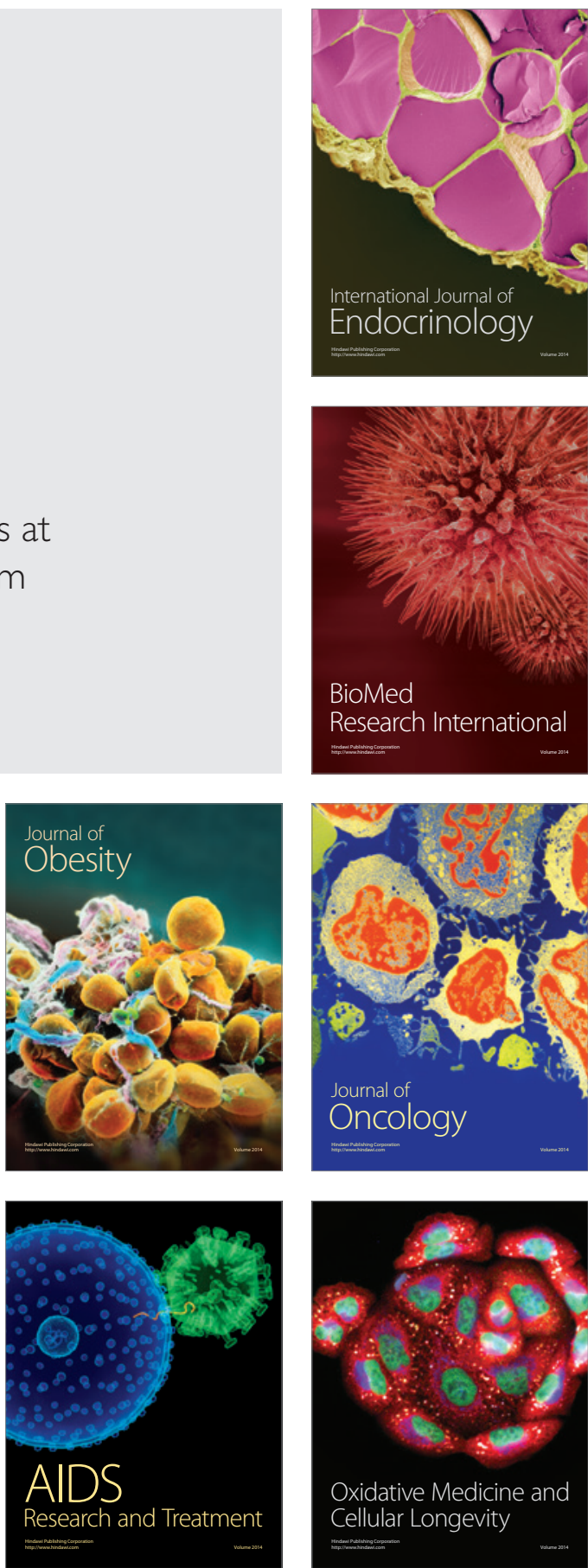